Disclosure of Interests: Vincenzo Venerito: None declared, Dorotea Natuzzi: None declared, Rita Bizzoca: None declared, Nunzia Lacarpia: None declared, Marco Fornaro: None declared, maria giannotta: None declared, giulia righetti: None declared, Giuseppe Lopalco: None declared, Florenzo lannone Consultant of: Speaker and consulting fees from AbbVie, Eli Lilly, Novartis, Pfizer, Roche, Sanofi, UCB, MSD, Speakers bureau: Speaker and consulting fees from AbbVie, Eli Lilly, Novartis, Pfizer, Roche, Sanofi, UCB, MSD

DOI: 10.1136/annrheumdis-2020-eular.4644

\section{AB0845 TOFACITINIB IMPROVES DISEASE ACTIVITY AND PATIENT-REPORTED OUTCOMES (PROS) IN PATIENTS (PTS) WITH ACTIVE PSORIATIC ARTHRITIS (PSA) IN REAL CLINICAL PRACTICE.}

T. Korotaeva ${ }^{1}$, L. Vorobyova ${ }^{1}$, E. Loginova ${ }^{1}$, E. Gubar ${ }^{1}$, Y. Korsakova ${ }^{1}$, S. Glukhova' ${ }^{1}$, P. Karpova ${ }^{1} .{ }^{1}$ Nasonova Research Institute of Rheumatology, Moscow, Russian Federation

Background: PsA is a disease with multiple manifestations; it has significant impact on physical and emotional aspects of pts' life. PROs as well as disease activity are an important instrument for assessing treatment response. Tofacitinib (TF) is an oral Janus kinase inhibitor; in RCT TF demonstrated efficacy in active PsA pts concerning PROs [1] but there is currently no evidence from real clinical practice.

Objectives: to study the influence of TF on disease activity and PROs in $3 / 6$ months (mo) of therapy in pts with active PsA in clinical practice.

Methods: $41(\mathrm{M} / \mathrm{F}=24(58.5 \%) / 17(41.5 \%)$ PsA pts fulfilling the CASPAR criteria were included. Mean age $42.4 \pm 10.3$ years (yrs), median (Me) PsA duration $72[35 ; 120] \mathrm{mo}$, pts had inadequate response to conventional synthetic disease-modifying antirheumatic drugs (csDMARDs, mostly Methotrexate)/biological (b) DMARDs (29\% of pts). Pts were treated with TF $5 \mathrm{mg}$ twice daily after signing consent participation forms. At baseline (BL) and in $3 / 6$ mo of therapy PsA activity was evaluated by Tender Joint Count (TJC68), Swollen Joint Count (SJC66); PGA, physician global assessment by Visual Analog Scale (VAS), DAPSA. PROs were measured by PtGA VAS, PtPain VAS, BASDAI, HAQ, DLQI, RAPID, FACIT, PsAID12, Patient-Acceptable Symptom State (PASS) of PsAID12 $\leq 4$. PsAID12 was analyzed as a change above the minimal clinical important difference (MCID) -1.25 points [2]. Higher PsAID12 scores are considered to be worse and correspond to poorer PsA-specific health-related quality of life. $M \pm S D, M e[Q 25 ; Q 75], \%$, t-test, Pierson- $x^{2}$, Manna-Whitney tests were performed. All $p<0.05$ were considered to indicate statistical significance.

Results: At BL $87.8 \%$ of pts had high PsA activity by DAPSA. By $3 / 6$ mo of therapy significant improvement in all PsA activity indexes and PROs were observed (table 1) (for all $p<0.0001$ ). By 6 mo of therapy DAPSA remission was seen in 11 out of 41 pts $(26.8 \%)$. After $3 / 6$ mo of therapy all PsAID12 domains demonstrated significant improvement $(p<0.0001)$ (Figure 1). The PsAID12 improvement above MCID in -1.25 points reached $90.2 \%$ of pts by 6 mo. In $3 / 6$ mo of therapy PsAID12 PASS was achieved in $66.7 \% / 71.8 \%$ pts accordingly.

Table 1. Change in all evaluated parameters from BL to $3 / 6 \mathrm{mo}$.

\begin{tabular}{|c|c|c|c|}
\hline Parameters, $\mathrm{M} \pm \mathrm{SD}$ & $B L$ & $3 \mathrm{mo}$ & $6 \mathrm{mo}$ \\
\hline TJC68 & $18.1 \pm 9.8$ & $6.3 \pm 6.9^{*}$ & $4.9 \pm 5.0^{\star \star}$ \\
\hline SJC66 & $12.8 \pm 7.7$ & $3.7 \pm 4.3^{\star}$ & $2.5 \pm 4.0^{\star \star}$ \\
\hline BASDAI & $6.0 \pm 1.7$ & $2.2 \pm 1.63^{*}$ & $1.77 \pm 1.42^{\star \star}$ \\
\hline DAPSA & $44.2 \pm 17.1$ & $15.2 \pm 12.4^{*}$ & $11.8 \pm 9.4^{\star *}$ \\
\hline $\operatorname{CRP}(\mathrm{mg} / \mathrm{l})$ & $27.4 \pm 29.3$ & $5.1 \pm 7.8^{*}$ & $6.2 \pm 11.6^{\star \star}$ \\
\hline PtPain, VAS, mm & $65[50 ; 75]$ & $20[10 ; 30]^{*}$ & $18[5 ; 30]^{*}$ \\
\hline PtGA, VAS, mm & $70[50 ; 80]$ & $23[14 ; 35]^{\star}$ & $20[10 ; 30]^{\star *}$ \\
\hline $\operatorname{ESR}(\mathrm{mm} / \mathrm{h})$ & $32 \pm 25.5$ & $14.8 \pm 16,3^{*}$ & $13.6 \pm 16.3^{\star \star}$ \\
\hline Total PsAID12 score (over past week, 0-10) & $5.18 \pm 2.14$ & $2.07 \pm 1.65^{*}$ & $1.68 \pm 1.48^{* *}$ \\
\hline PSAID12 PASS, $\%$ & 25.6 & 66.7 & 71.8 \\
\hline $\mathrm{HAQ}$ & $1[0.625 ; 1.5]$ & $0.5[0.125 ; 0.875]^{\star}$ & ${ }^{\star} 0.5[0 ; 0.875]^{\star \star}$ \\
\hline DLQI & $5[2 ; 12]$ & $2[0 ; 6]^{*}$ & $2[0 ; 4]^{\star *}$ \\
\hline FACIT & $29[23 ; 38]$ & $39.5[31.5 ; 48]^{\star}$ & $38[32 ; 45]^{\star *}$ \\
\hline RAPID & $16[13.3 ; 18.6]$ & ] $6.5[3.7 ; 9.1]^{\star}$ & $5[2.3 ; 8.3]^{\star \star}$ \\
\hline
\end{tabular}

${ }^{*} p<0.0001$ - differences from $B L$ to $3 \mathrm{mo} ;{ }^{* \star} p<0.0001$ - differences from BL/6 mo;

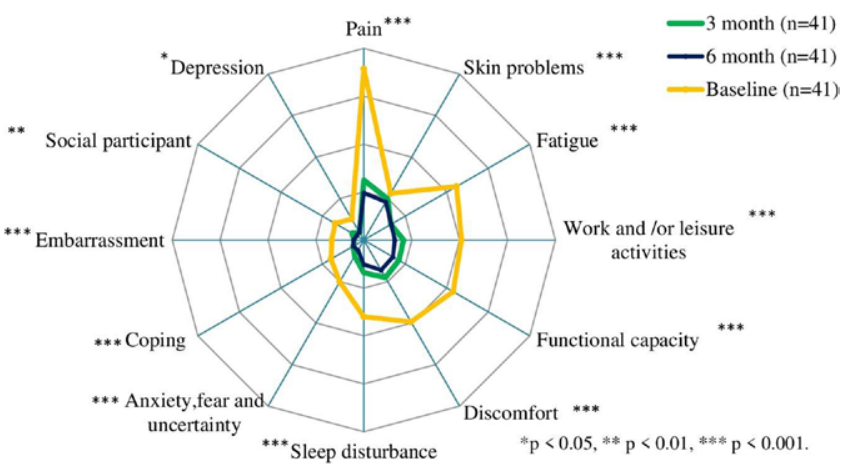

Figure 1. PsAID12 domains at $B L$ and at $3 / 6$ mo of TF treatment.

Conclusion: In real clinical practice TF provides significant and clinically considerable improvement of PsA activity and PROs, including pain, psychological and emotional status.

References:

[1] Strand V, et al. RMD Open 2019;5:e000806. doi:10.1136/ rmdopen-2018-000806.

[2] Holland R, et al. Ann Rheum Dis. 2018;77:343-47.

Disclosure of Interests: Tatiana Korotaeva Consultant of: Pfizer, MSD, Novartis, AbbVie, Celgene, JSC BIOCAD, Janssen, UCB, Lilly and Novartis-Sandoz, Speakers bureau: Pfizer, MSD, Novartis, AbbVie, Celgene, JSC BIOCAD, Janssen, UCB, Lilly and Novartis-Sandoz, Lyubov Vorobyova: None declared, Elena Loginova Speakers bureau: Janssen, ELENA GUBAR: None declared, Yulia Korsakova: None declared, Svetlana Glukhova: None declared, Polina Karpova: None declared

DOI: 10.1136/annrheumdis-2020-eular.2620

\section{AB0846 HIGH DEGREE OF CLASSIFICATION CRITERIA FULFILLMENT AMONG PATIENTS WITH CLINICAL PSORIATIC ARTHRITIS DIAGNOSES IN SWEDEN}

J. K. Wallman ${ }^{1,2}$, G. M. Alenius ${ }^{3,4}$, E. Klingberg ${ }^{5,6}$, V. Sigurdardottir ${ }^{7}$, S. Wedrén ${ }^{8}$ S. Exarchou ${ }^{1}$, U. Lindström ${ }^{5}$, D. DI Giuseppe ${ }^{9}$, J. Askling ${ }^{9}$, L. T. H. Jacobsson ${ }^{5}$.

${ }^{1}$ Lund University, Lund, Sweden; ${ }^{2}$ Skåne University Hospital, Lund, Sweden;

${ }^{3}$ Umeå University, Umeå, Sweden; ${ }^{4}$ Norrland University Hospital, Umeå,

Sweden; ${ }^{5}$ University of Gothenburg, Gothenburg, Sweden; ${ }^{6}$ Sahlgrenska University Hospital, Gothenburg, Sweden; ${ }^{7}$ Falun Hospital, Falun, Sweden;

${ }^{8}$ Karolinska University Hospital, Stockholm, Sweden; ${ }^{9}$ Karolinska Institutet, Stockholm, Sweden

Background: The clinical diagnosis of psoriatic arthritis (PsA) may be challeng ing. In Sweden, the vast majority of PsA cases are diagnosed within rheumatology or internal medicine (IM). Knowledge of the correspondence between clinical ICD diagnoses and classification criteria fulfillment is crucial to interpret studies identifying cases based on ICD codes.

Objectives: To assess the degree to which patients with clinical PsA diagnoses in Sweden fulfill established PsA classification criteria.

Methods: Four hundred patients with $\geq 1$ outpatient physician visit to one of five rheumatology or IM departments (3 university/2 county departments, spread across Sweden) 2013-2015 with a main ICD-10 diagnosis of PsA (L40.5/M07.0-M07.3), were randomly selected from the Swedish Nationa Patient Register (80 cases/site). Based on a structured medical record review, positive predictive values (PPV) of a clinical PsA diagnosis (i.e. $\geq 1$ visit with a PSA ICD-10 code) for fulfillment of the following classification criteria were assessed: CASPAR,[1] Moll \& Wright,[2] Vasey \& Espinoza,[3] and Modified ESSG criteria for PsA,[4] respectively (as well as for any of these); ASAS criteria for peripheral or axial spondyloarthritis (SpA) [5]; and the 1987 ACR criteria for rheumatoid arthritis (RA).[6] Subanalyses regarding CASPAR fulfillment were also performed restricted to patients with available rheumatoid factor and peripheral X-ray status (central CASPAR items; $n=227$ ), and among patients with $\geq 2$ ICD codes for $P s A$, of which $\geq 1$ from a rheumatology/IM department $(n=353)$.

Results: Out of 400 clinically diagnosed PsA patients, 343 (86\%) fulfilled any of the 4 PsA classification criteria, with a PPV for CASPAR fulfillment of $69 \%$ (rising to $73-82 \%$ in the subanalyses; Figure 1). Substantial overlap was seen 